\title{
Solitary Bone Cyst
}

\author{
Brenda L. Nelson
}

Received: 5 April 2010/Accepted: 7 April 2010/Published online: 20 April 2010

(C) US Government 2010

\begin{abstract}
A classic solitary bone cyst is discussed. Radiology and histology is reviewed.

Keywords Traumatic bone cavity - Cyst .

Idiopathic bone cyst · Hemorrhagic bone cyst · Ganathic
\end{abstract}

\section{History}

A 19 year-old male presents to the dentist for a routine dental examination. Radiographs showed a lesion of the posterior mandible. The associated teeth tested vital and the patient could not recall any history of pain, swelling or trauma to the area.

\section{Radiographic Features}

Panographic radiograph showed a well-delineated radiolucent lesion of the posterior left mandible. The superior border of the lesion appears to project up, or scallop, between the roots. No root resorption was noted (Fig. 1).

\section{Diagnosis}

Histological examination of hematoxylin and eosin stained slides demonstrated fragments of fibrovascular connective tissue, scant bone fragments and numerous extravasated

\section{B. L. Nelson $(\square)$}

Department of Anatomic Pathology, Naval Medical Center

San Diego, 34800 Bob Wilson Drive, San Diego,

CA 92134-5000, USA

e-mail: brenda.nelson@med.navy.mil red blood cells (Fig 2). The specimen was notable for the lack of epithelium.

\section{Discussion}

A solitary bone cyst is a benign cavity in bone that is either empty or contains fluid. Despite its name, epithelium is not found. It is known by numerous other names, many of which also erroneously implying the presence of epithelium, and some of which try to explain possible etiologies. These names include: traumatic bone cyst, traumatic bone cavity, simple bone cyst, idiopathic bone cyst, and hemorrhagic bone cyst among others. The etiology is unknown, with proposed causes ranging from trauma to developmental.

Over $90 \%$ of solitary bone cysts are located in long bones, most commonly the proximal humerus and femur. Of the less than $10 \%$ that are found in the ganathic bones, the mandible is favored over three quarters of the time $[1,2]$. In either the maxilla or mandible, the posterior, premolar-molar area, is the most common location. Rare multifocal lesions are occasionally encountered in the literature [1]. Reports vary; however, males appear to be affected slightly more frequently than females [3]. The mean age of those affected is 20 years, with the lesion being decidedly less common after the end of the third decade [4]. Solitary bone cysts are generally asymptomatic and are usually detected on routine dental radiographs.

Radiographically, solitary bone cysts are variably sized radiolucent lesions with smooth well-defined to poorly defined borders. The lesion is classically said to scallop, or push up, around associated roots. Root resorption is uncommon and associated teeth should test vital. Larger lesions may have a vague multilocular appearance and 


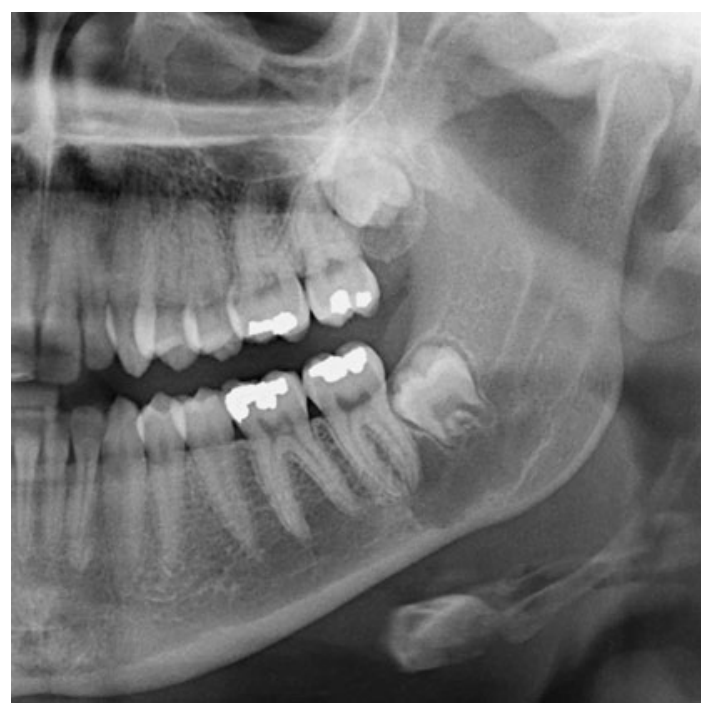

Fig. 1 A panographic radiograph shows a radiolucent lesion apical to the left mandibular molars. Note the scalloping superior aspect

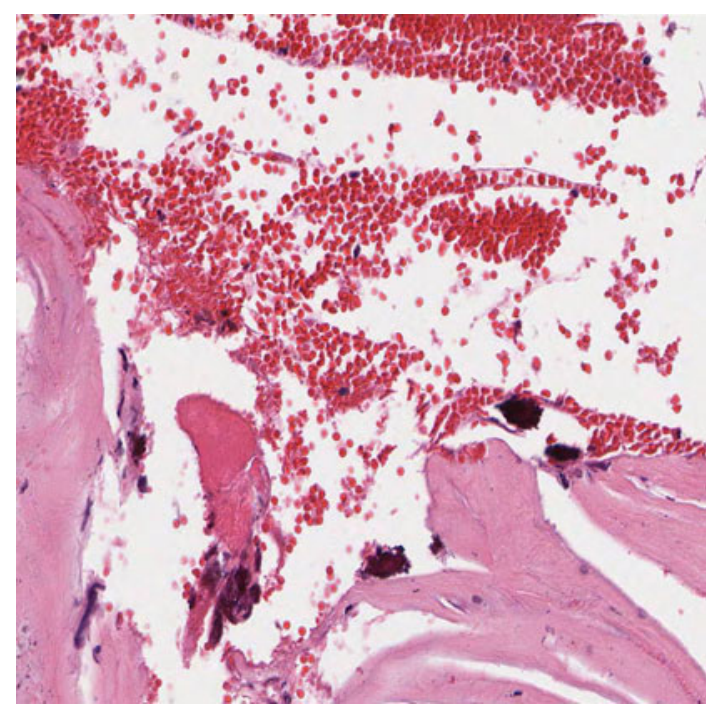

Fig. 2 Photomicrograph of the typically scant specimen submitted from a solitary bone cyst. Fragments of fibrovascular connective tissue, calcified material and red blood cells are noted

even occasionally cause bone expansion. There is evidence to support that those solitary bone cysts that are multilocular, expansile and associated with root resoprtion may resolve slower with standard treatment [5].
Histologically, the solitary bone cyst is remarkable for its lack of tissue. Generally, the submitted tissue consists of scant fragments of fibrovascular connective tissue, extravasated red blood cells and pieces of reactive vital bone. No cystic epithelium is identified. Often times the scarcity of tissue makes rendering a diagnosis difficult, however, the intraoperative finding of an empty or fluid filled space is supportive of a solitary bone cyst.

Treatment of solitary bone cysts of the gnathic bones is surgical. Curettage of the boney walls, and often the biopsy procedure itself, will incite healing. Resolution generally takes about 6 months; larger lesions may take longer [4]. Follow up is indicated, however, the prognosis is excellent.

Disclaimer The opinions and assertions expressed herein are those of the author and are not to be construed as official or representing the views of the Department of the Navy or the Department of Defense.

\section{References}

1. Kuhmichel A, Bouloux GF. Multifocal traumatic bone cysts: case report and current thoughts on etiology. J Oral Maxillofac Surg. 2010;68(1):208-12. (PubMed PMID: 20006180).

2. Harnet JC, Lombardi T, Klewansky P, Rieger J, Tempe MH, Clavert JM. Solitary bone cyst of the jaws: a review of the etiopathogenic hypotheses. J Oral Maxillofac Surg. 2008;66(11): 2345-8. (Review. PubMed PMID: 18940504).

3. Xanthinaki AA, Choupis KI, Tosios K, Pagkalos VA, Papanikolaou SI. Traumatic bone cyst of the mandible of possible iatrogenic origin: a case report and brief review of the literature. Head Face Med. 2006;2:40. (PubMed PMID: 17096860; PubMed Central PMCID: PMC1660580).

4. Cortell-Ballester I, Figueiredo R, Berini-Aytés L, Gay-Escoda C. Traumatic bone cyst: a retrospective study of 21 cases. Med Oral Patol Oral Cir Bucal. 2009;14(5):E239-43. (PubMed PMID: 19218905).

5. Suei Y, Taguchi A, Nagasaki T, Tanimoto K. Radiographic findings and prognosis of simple bone cysts of the jaws. Dentomaxillofac Radiol. 2010;39(2):65-72. (PubMed PMID: 20100916). 